\title{
The impact of antibiotics on the metabolic status of obese adults without bacterial infection: a systematic review and meta-analysis
}

\author{
Naofumi Yoshida ${ }^{1,2^{\wedge}}$, Yoshihiro Saito ${ }^{1}$, Yasushi Tsujimoto ${ }^{2,3,4^{\wedge}}$, Shunsuke Taito ${ }^{2,5^{\wedge}}$, Masahiro Banno ${ }^{2,6,7^{\wedge}}$, \\ Yuki Kataoka $^{2,8^{\wedge}}$, Tomoya Yamashita ${ }^{\wedge}$, Ken-ichi Hirata ${ }^{1}$ \\ ${ }^{1}$ Division of Cardiovascular Medicine, Department of Internal Medicine, Kobe University Graduate School of Medicine, Kobe, Japan; ${ }^{2}$ Systematic \\ Review Workshop Peer Support Group (SRWS-PSG), Japan; ${ }^{3}$ Department of Nephrology and Dialysis, Kyoritsu Hospital, Kawanishi, Japan; \\ ${ }^{4}$ Healthcare Epidemiology, School of Public Health in the Graduate School of Medicine, Kyoto University, Kyoto, Japan; ${ }^{5}$ Division of Rehabilitation, \\ Department of Clinical Practice and Support, Hiroshima University Hospital, Hiroshima, Japan; ${ }^{6}$ Department of Psychiatry, Seichiryo Hospital, \\ Nagoya, Japan; ${ }^{7}$ Department of Psychiatry, Nagoya University Graduate School of Medicine, Nagoya, Japan; ${ }^{8}$ Hospital Care Research Unit, Hyogo \\ Prefectural Amagasaki General Medical Center, Amagasaki, Japan \\ Contributions: (I) Conception and design: N Yoshida, Y Saito, Y Tsujimoto, S Taito, M Banno, Y Kataoka; (II) Administrative support: All authors; \\ (III) Provision of study materials or patients: All authors; (IV) Collection and assembly of data: N Yoshida, Y Saito, Y Tsujimoto, S Taito, M Banno, Y \\ Kataoka; (V) Data analysis and interpretation: N Yoshida, Y Saito, Y Tsujimoto, S Taito, M Banno, Y Kataoka; (VI) Manuscript writing: All authors; \\ (VII) Final approval of manuscript: All authors. \\ Correspondence to: Naofumi Yoshida, MD, PhD. Division of Cardiovascular Medicine, Department of Internal Medicine, Kobe University Graduate \\ School of Medicine, 7-5-1 Kusunoki-cho, Chuo-ku, Kobe 6500017, Japan. Email: kouchiboy@hotmail.com.
}

\begin{abstract}
Background: The gut microbiota is involved in the pathophysiology of obesity. It is known that oral antibiotics manipulate the gut microbiota; however, the impact on host metabolism of obese adults without bacterial infection has not been systematically summarized.

Methods: We searched for randomized, placebo-controlled trials that investigated the effects of oral antibiotics on the metabolic status in obese adults via Medline, EMBASE, and the Cochrane Library. Primary outcomes were homeostasis model assessment of insulin resistance (HOMA-IR), body weight, and rate of diarrhea. Additional outcomes included fasting plasma glucose (FPG), plasma glucagon-like peptide-1 (GLP1), waist circumference, fecal short-chain fatty acid (SCFA) levels, and all adverse events. We assessed the certainty of evidence based on Grading of Recommendations, Assessment, Development and Evaluations.

Results: Among 1,762 articles screened, four studies were eligible for quantitative analysis, two of which were applied to meta-analysis. Oral antibiotics had low influence on HOMA-IR [mean difference (MD) 0.09 (95\% CI: -0.96 to 1.13$)$ ], body weight [MD $4.1 \mathrm{~kg}$ (95\% CI: -23.77 to 31.97)], FPG [MD $-0.12 \mathrm{mmol} / \mathrm{L}$ (95\% CI: -0.47 to 0.23 )], and GLP-1 [MD $0.20 \mathrm{pmol} / \mathrm{L}$ (95\% CI: -2.36 to 2.76 )] compared to placebo. Antibiotics treatment altered fecal acetate and butyrate levels, but resulted in little difference in propionate levels [MD $-13.60 \mu \mathrm{mol} / \mathrm{g}$ (95\% CI: -22.43 to -4.77$), \mathrm{MD}-7.60 \mu \mathrm{mol} / \mathrm{g}(-10.97$ to -4.23$), \mathrm{MD}-1.10 \mu \mathrm{mol} / \mathrm{g}$ (95\% CI: -4.18 to 1.98 ), respectively]. Several adverse events, such as sun sensitivity and gastrointestinal discomfort, were reported following antibiotics treatment, but no diarrhea. The certainty of evidence for most outcomes was very low to low, except for fecal SCFAs.

Conclusions: Our results indicate that oral antibiotics treatment is insufficient to ameliorate metabolic parameters in obese adults, suggesting that oral antibiotics treatment may not qualify as a therapeutic approach for obesity.
\end{abstract}

Keywords: Overweight; antibiotics; systematic review; meta-analysis

\footnotetext{
^ Naofumi Yoshida ORCID: 0000-0003-3949-0089; Yasushi Tsujimoto ORCID: 0000-0002-7214-5589; Shunsuke Taito ORCID: 00000003-1218-4225; Masahiro Banno ORCID: 0000-0002-2539-1031; Yuki Kataoka ORCID: 0000-0001-7982-5213; Tomoya Yamashita ORCID: 0000-0003-0267-3842.
} 
Submitted Feb 10, 2020. Accepted for publication Jul 18, 2020.

doi: 10.21037/atm-20-1007a

View this article at: http://dx.doi.org/10.21037/atm-20-1007a

\section{Introduction}

Obesity results from complex interactions such as metabolic, genetic, and physiologic factors as well as social, environmental, and lifestyle factors (1). Obesity predisposes to an inflammatory state, which contributes to the development of metabolic abnormalities, such as insulin resistance and dyslipidemia, as well as cardiovascular diseases (2). Obesity has recently emerged as a condition with rising demand for treatment due to the dramatic increase in its prevalence (3); therefore, it is very important to combat obesity, which will consequently help prevent associated health problems. Recent clinical and basic research has suggested that the gut microbiota is one of the most recently recognized factors playing a critical role in obesity development (4), as it regulates nutrient extraction from the daily diet (5), intestinal barrier function via tight junction permeability, systemic endotoxemia (6), and production of multiple signaling molecules, such as short-chain fatty acids (SCFAs) (7). Next-generation sequencing techniques and multi-omics approaches have dramatically expanded our knowledge of the microbial world, and have provided insights into the characteristics of the gut microbiota in obese subjects, highlighting the functional difference between obese and non-obese subjects $(8,9)$. Although the number and diversity of gut bacteria is higher in the colon than in the small intestine, a low-pH compartment with short transit times (10), an in vivo study has recently reported that altered gut microbiota in the small intestine also have an impact on glucose metabolism (11). Furthermore, it was also shown that germ-free mice, which were fed a high fat diet, were protected against obesity and insulin resistance (12). Based on this evidence, several trials assessed the effects of oral antibiotics administration on the metabolism of obese individuals via altering the gut microbiota (13-15). However, the outcomes of interest varied across studies, and it still remains unclear whether oral antibiotics treatment could apply for clinical settings to improve the metabolic status in obese subjects. We therefore systematically summarized current evidence on the impact of oral antibiotics on selected metabolic parameters, such as homeostasis model assessment of insulin resistance (HOMA-IR), body weight, fasting plasma glucose (FPG) levels, and plasma glucagon-like peptide-1 (GLP-1) levels in obese subjects. We included fecal SCFA levels, which reflect gut microbial profile alterations following antibiotics treatment, as one of the secondary outcomes. The ultimate goal of the present study is to reveal whether oral antibiotics will be helpful in identifying novel treatment options for obesity and associated diseases. We present the following article in accordance with the PRISMA reporting checklist (available at http://dx.doi.org/10.21037/atm-20-1007a) (16).

\section{Methods}

\section{Compliance with reporting guidelines}

We conducted a systematic review according to the Preferred Reporting Items for Systematic Reviews and Meta-Analyses (PRISMA) guidelines (17) and the recommendations listed in the Cochrane Handbook (18).

\section{Research question and eligibility criteria}

The research question addressed in the present study was: "Do oral antibiotics have an impact on the metabolic status of obese adults having no bacterial infection?" We included both published and unpublished data sets of individual, cluster, and cross-over randomized controlled trials (RCTs) in our analysis. We excluded quasi-RCTs, non-randomized studies, and observational studies, but included all relevant studies, irrespective of language, publication year, and country of origin.

A patient was defined as an adult subject (age $\geq 18$ years) with obesity (body mass index $\geq 25 \mathrm{~kg} / \mathrm{m}^{2}$ ), but we excluded cases of active infection or antibiotics intake for treatment of other diseases. The term intervention was defined as an administration of oral antibiotics. All kinds of oral antibiotics and intervention periods were included in this study. Comparison/control groups were defined as patients subjected to placebo treatment, non-intervention, or usual care.

\section{Outcomes of interest}

The primary outcomes of interest were HOMA-IR, body 
weight, and rate of diarrhea. HOMA-IR was calculated as (insulin $\times$ FPG)/405. The secondary outcomes were FPG, plasma GLP-1, waist circumference, fecal SCFA levels, and all adverse events. We defined the timing of measurement of HOMA-IR, body weight, FPG, GLP-1, waist circumference, and fecal SCFAs as directly following intervention. We planned to calculate the rate of diarrhea as total incidence of diarrhea per intervention period. For all adverse events, a qualitative report was included instead of performing meta-analysis.

\section{Search strategy and selection of studies}

We searched MEDLINE via PubMed, EMBASE via Proquest Dialog, and the Cochrane Central Register of Controlled Trials (CENTRAL) for RCT, which were designed to investigate the clinical effects of oral antibiotic treatment on the metabolism of obese individuals having no bacterial infection. The detailed retrieval strategy is shown in Tables S1-S3. Two researchers (NY, YS) carried out the search for other relevant research by hand-searching the reference lists of the studies screened, and those of articles citing such studies. After duplicates were removed, two researchers (NY, YS) independently screened the articles by checking whether the study titles and abstracts contained information relevant to the present study using Rayyan (19). In case of any disagreement between NY and YS, a third researcher (YT, ST, MB, YK) acted as an arbiter. Finally, we assessed the eligibility based on the full text.

\section{Data extraction}

We abstracted general information including study design, authors, publication year, country of origin, and baseline characteristics (sample size, mean age, and sex distribution), as well as primary and additional outcomes of interest. For continuous data, we reported results of the individual outcomes as mean and standard deviation (SD). In cases where the authors reported the continuous data as median and Standard Error of the Mean or interquartile range, we converted the indicated values to mean \pm SD according to the Cochrane Handbook for Systematic Reviews of Interventions (18). When multiple intervention groups existed in an RCT, the mean and SDs in each intervention group were integrated (18). All extracted data were summarized in electronic spreadsheets.

\section{Dealing with missing data}

For missing data on individual outcomes, we contacted the corresponding author within a period of two weeks through email, and reminded him/her up to two times. For cases lacking a response from the author, we decided not to impute the missing values.

\section{Quality assessment}

Two researchers (NY, YS) independently used a revised tool for assessing risk of bias in randomized trials (RoB 2) (20). Differences in opinion were resolved mostly through discussion between the two researchers, and occasionally with the help of a third researcher (YT, ST, $\mathrm{MB}$, and $\mathrm{YK}$ ). To summarize the evidences, we followed the Grading of Recommendations, Assessment, Development and Evaluation (GRADE) approach, and prepared Summary of Findings (SoF) tables (21) for the outcomes of interest, such as HOMA-IR, body weight, rate of diarrhea, plasma GLP-1 levels, and fecal SCFA levels.

\section{Statistical analysis}

We used the Cochrane Review Manager software (RevMan V.5.3; Cochrane Collaboration, Copenhagen, Denmark) to manage the data and carry out the random-effects model meta-analysis (22). We reported the results of the outcomes as mean difference (MD), which is the difference in the mean values of intervention and control groups. We also reported all effect sizes alongside $95 \%$ confidence intervals (CI). Heterogeneity was assessed using the $\mathrm{I}^{2}$ index (23). In the case where $\mathrm{I}^{2}>50 \%$ was identified for an outcome, we investigated the underlying reasons and conducted the $\chi^{2}$ test, considering a $\mathrm{P}$ value $<0.10$ to indicate statistical significance. The use of the Egger test for detecting reporting bias was intended. We further planned prespecified sensitivity analyses for the primary outcomes, if required, as well as subgroup analysis according to the type of antibiotics intervention, if there would be more than one RCT for each antibiotic.

\section{Ethics and dissemination}

Due to the nature of this study, no ethical issues are foreseen. This study was registered with the International prospective register of systematic reviews (CRD42020157406). 


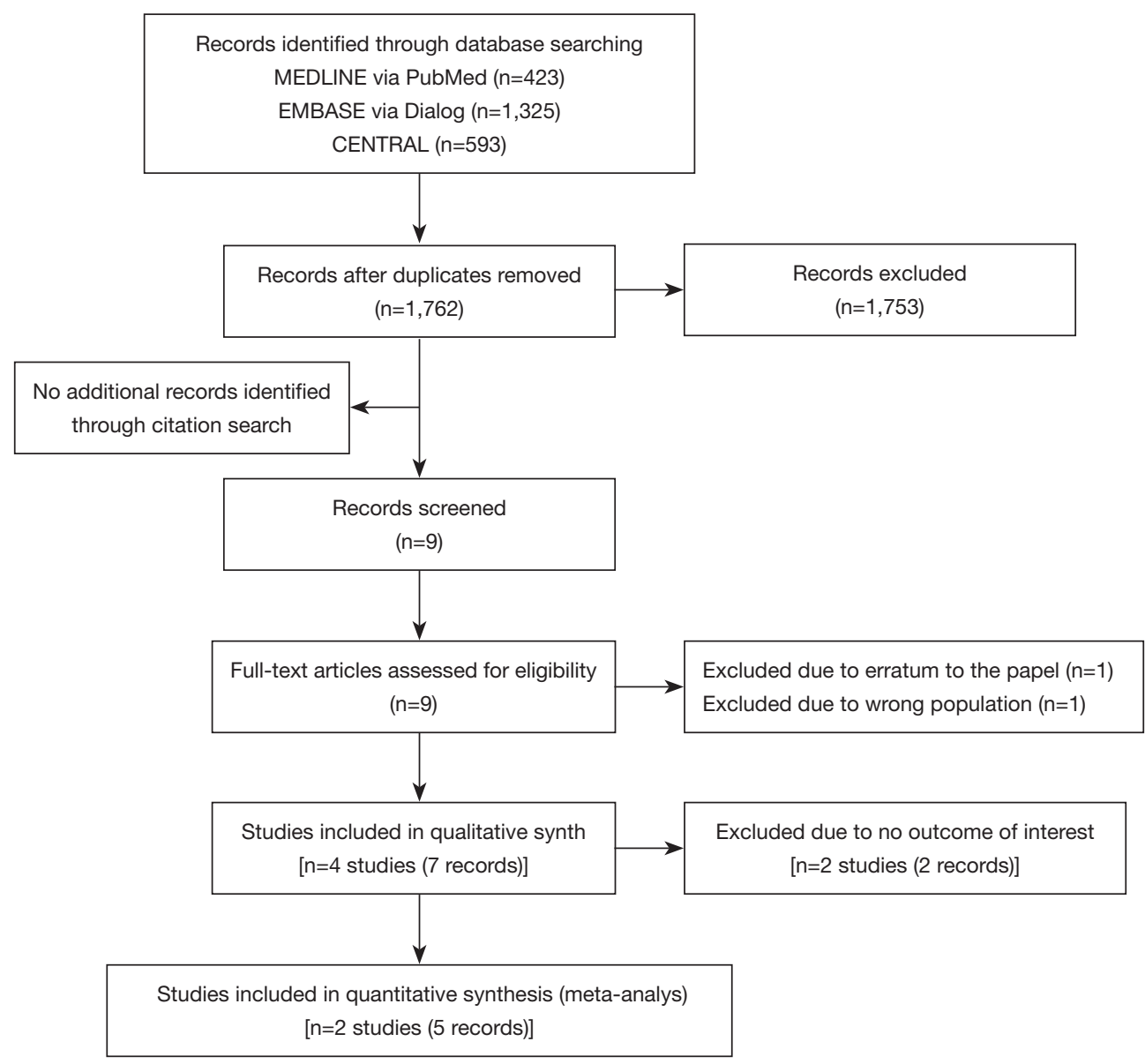

Figure 1 PRISMA flow diagram.

\section{Results}

\section{Search results and characteristics of included trials}

We identified 1,762 records during the search conducted in December 2019. Nine full-text records were assessed for their eligibility for the present study, out of which two articles were excluded, as one of them was an erratum to a paper already included (24), while the other was a protocol article, which included subjects suffering from diabetes mellitus, not obesity (25) (Figure 1). We finally included four individual RCTs $(\mathrm{n}=165)$ that fulfilled all the eligibility criteria (13,15,26-30) (Figure 1).

As shown in Table 1, three of the RCTs were performed in the U.S.A., and one in the Netherlands. The mean or median age of the subjects in the RCTs ranged from 45 to 61 years, with sample sizes of 18 to 66 . One of the studies included only male subjects (15).

The oral antibiotics used in these studies were doxycycline (DOX) (200 mg/day and dose unknown), rifaximin at $1,100 \mathrm{mg} /$ day, amoxicillin (AMOX) at $1,500 \mathrm{mg} /$ day, and vancomycin (VANCO) at $1,500 \mathrm{mg} /$ day.

As we did not obtain any outcome data of interest even after approaching the corresponding authors of two RCTs $(26,28)$, we included the two remaining RCTs (5 records) in the meta-analysis $(13,15,27,29,30)$ (Figure 1). Figure 2 shows the methodological quality of included studies. Both studies reported concerns about or a high risk of bias for the indicated outcomes.

\section{Primary outcomes}

Table 2 shows a summary of the findings of the present study.

Compared with placebo, antibiotics caused little to no difference in HOMA-IR [MD 0.09 (95\% CI: -0.96 to 1.13)] (Figure 3A). Body weight was measured in one trial (14), but 


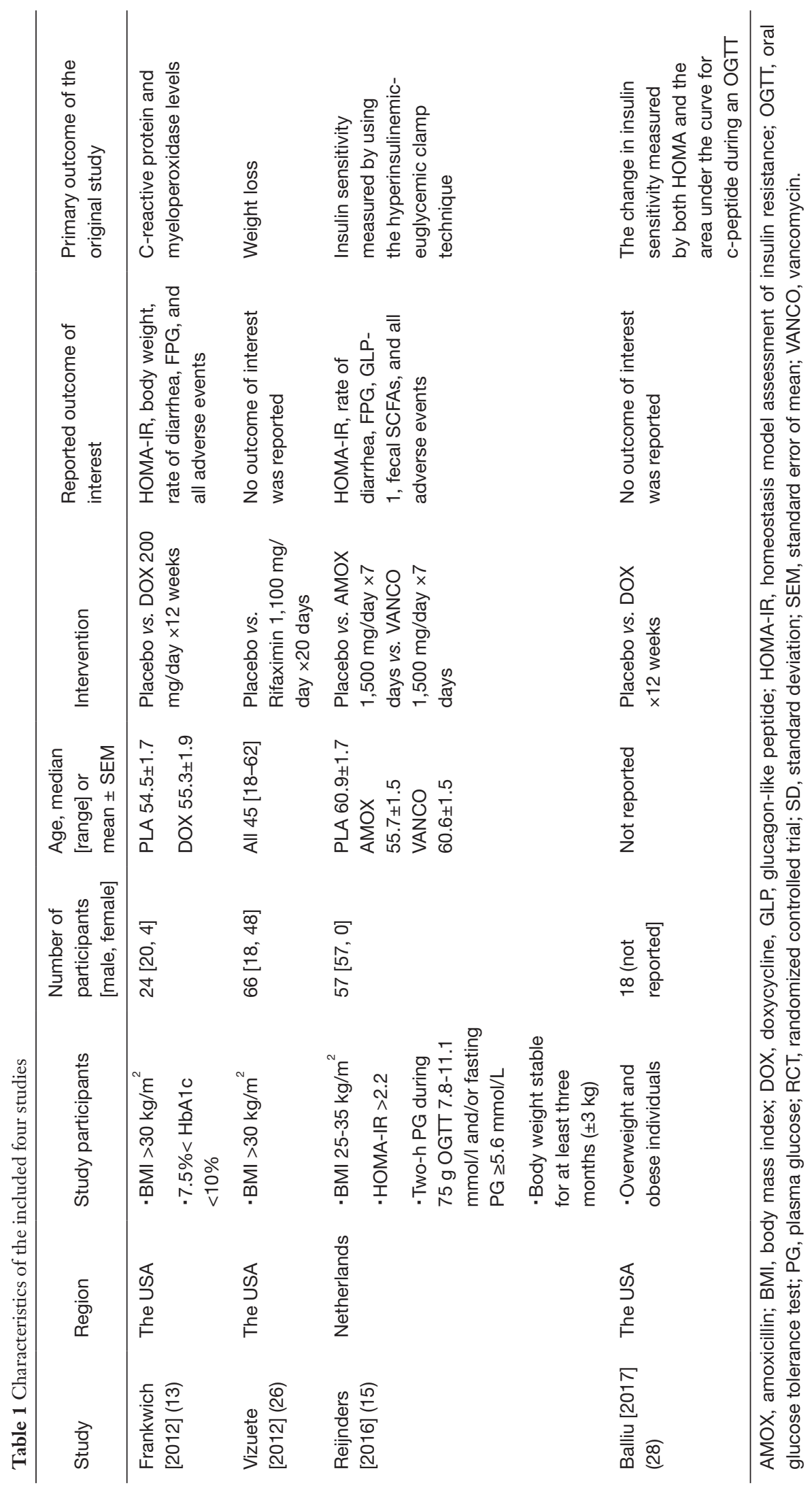




\begin{tabular}{|c|c|c|c|c|c|c|c|}
\hline \multirow[t]{2}{*}{ Outcome } & \multirow[t]{2}{*}{ Study } & \multicolumn{6}{|c|}{ Risk of bias 2 tool assessment } \\
\hline & & $\begin{array}{l}\text { Bias arising } \\
\text { from the } \\
\text { randomizati } \\
\text { on process }\end{array}$ & $\begin{array}{l}\text { Bias due to } \\
\text { deviations } \\
\text { from } \\
\text { intended } \\
\text { intervention } \\
\mathrm{s}\end{array}$ & $\begin{array}{l}\text { Bias due to } \\
\text { missing } \\
\text { outcome } \\
\text { data }\end{array}$ & $\begin{array}{l}\text { Bias in } \\
\text { measurem } \\
\text { ent of the } \\
\text { outcome }\end{array}$ & $\begin{array}{l}\text { Bias in } \\
\text { selection of } \\
\text { the } \\
\text { reported } \\
\text { result }\end{array}$ & $\begin{array}{l}\text { Over all } \\
\text { risk of bias }\end{array}$ \\
\hline \multirow{2}{*}{ HOMA-IR } & $\begin{array}{l}\text { Frankwich } \\
2012\end{array}$ & & & & & & \\
\hline & $\begin{array}{l}\text { Reijnders } \\
2016\end{array}$ & & & & & & \\
\hline $\begin{array}{l}\text { Body } \\
\text { weight }\end{array}$ & $\begin{array}{l}\text { Frankwich } \\
2012\end{array}$ & & & & & & \\
\hline \multirow{2}{*}{$\begin{array}{l}\text { Rate of } \\
\text { diarrhea }\end{array}$} & $\begin{array}{l}\text { Frankwich } \\
2012\end{array}$ & & & & & & \\
\hline & $\begin{array}{l}\text { Reijnders } \\
2016\end{array}$ & & & & & & \\
\hline \multirow{2}{*}{ FPG } & $\begin{array}{l}\text { Frankwich } \\
2012\end{array}$ & & & & & & \\
\hline & $\begin{array}{l}\text { Reijnders } \\
2016\end{array}$ & & & & & & \\
\hline $\begin{array}{l}\text { Glucagon- } \\
\text { like } \\
\text { peptide-1 }\end{array}$ & $\begin{array}{l}\text { Reijnders } \\
2016\end{array}$ & & & & & & \\
\hline $\begin{array}{l}\text { Waist } \\
\text { circumferen } \\
\text { ce }\end{array}$ & $\begin{array}{l}\text { No study } \\
\text { reported the } \\
\text { outcome }\end{array}$ & - & - & - & - & - & - \\
\hline $\begin{array}{l}\text { Fecal } \\
\text { SCFAs }\end{array}$ & $\begin{array}{l}\text { Reijnders } \\
2016\end{array}$ & & & & & & \\
\hline \multirow{2}{*}{$\begin{array}{l}\text { All adverse } \\
\text { events }\end{array}$} & $\begin{array}{l}\text { Frankwich } \\
2012\end{array}$ & & & & & & \\
\hline & $\begin{array}{l}\text { Reijnders } \\
2016\end{array}$ & & & & & & \\
\hline
\end{tabular}

Figure 2 Risk of bias assessment for indicated outcomes. Risk of bias was assessed by version 2 of the Cochrane risk-of-bias tool for randomized trials (RoB 2). FPG, fasting plasma glucose; HOMA-IR, homeostasis model assessment of insulin resistance; SCFA, short-chain fatty acid.

it was uncertain whether antibiotics resulted in a decrease due to its wide CI [MD $4.1 \mathrm{~kg}$ higher (95\% CI: -23.77 to 31.97)] (Figure 3B). No diarrhea was observed in both the control and antibiotics groups (Table 2). The quality of evidence in all groups was characterized by a very low to low certainty of evidence due to limitations in study design and imprecision. Performing an Egger test for detecting reporting bias was planned; however, it could not be applied due to a limited number of trials (31). We were not able to carry out pre-specified sensitivity analyses for the primary outcomes, or subgroup analysis according to the type of antibiotics intervention, because the number of studies was insufficient.

\section{Secondary outcomes}

Compared with placebo controls, antibiotics treatment had virtually no impact on FPG levels [MD $-0.12 \mathrm{mmol} / \mathrm{L}$ (95\% CI: -0.47 to 0.23 )] (Figure $4 A$ ). GLP-1 levels were measured in one trial (15) and were demonstrated to be largely unaffected by antibiotics treatment [MD $0.20 \mathrm{pmol} / \mathrm{L}$ (95\% CI: -2.36 to 2.76$)$ ] 


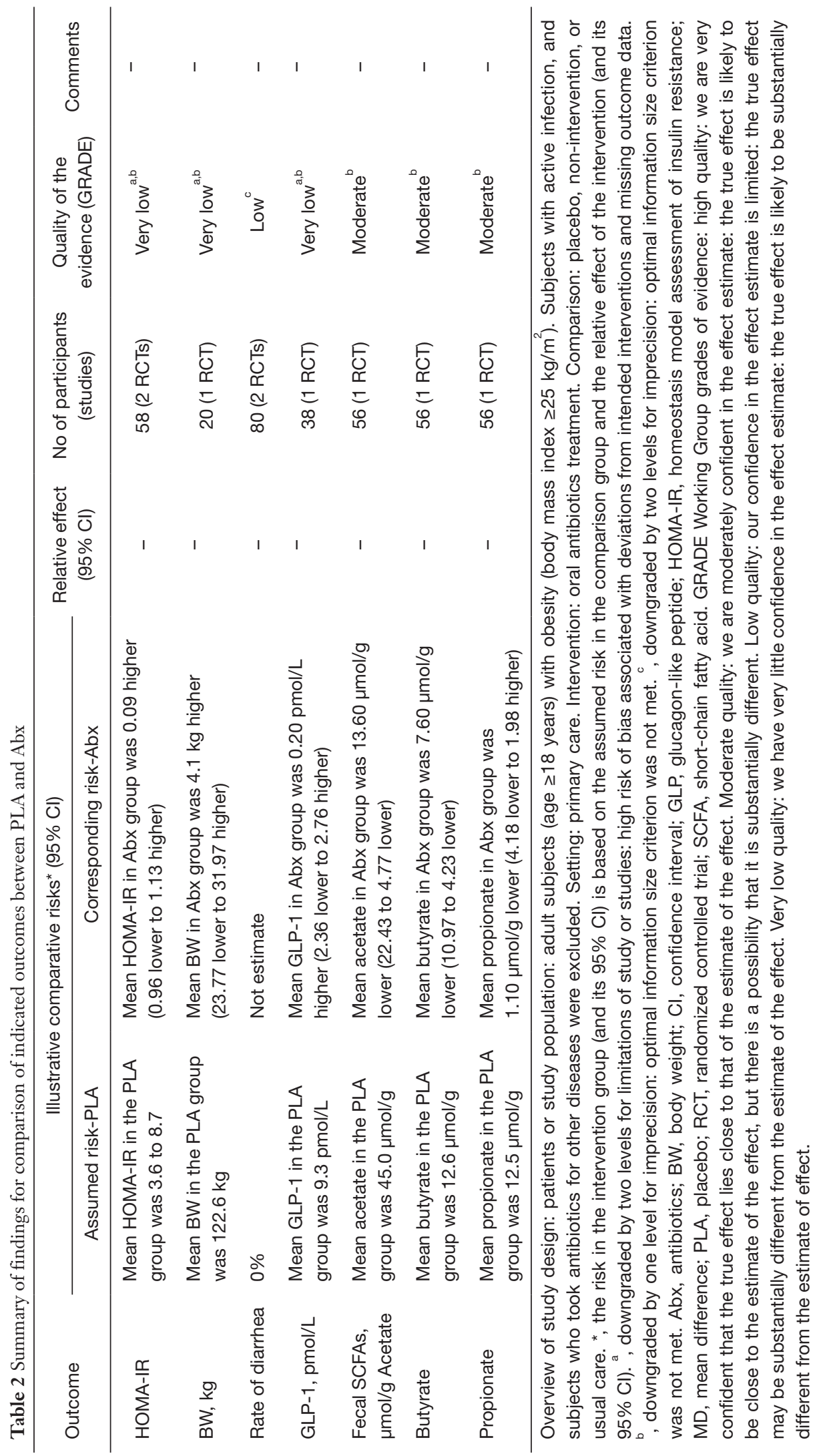




\section{A. HOMA-IR}

\begin{tabular}{|c|c|c|c|c|c|c|c|c|c|}
\hline \multirow[b]{2}{*}{ Study or Subgroup } & \multicolumn{3}{|c|}{$A b x$} & \multicolumn{3}{|c|}{ PLA } & \multirow[b]{2}{*}{ Weight } & \multirow{2}{*}{$\begin{array}{l}\text { Mean Difference } \\
\text { IV, Random, } 95 \% \mathrm{Cl}\end{array}$} & \multirow{2}{*}{$\begin{array}{c}\text { Mean Difference } \\
\text { IV, Random, } 95 \% \mathrm{CI} \\
\end{array}$} \\
\hline & Mean & SD & Total & Mean & SD & Total & & & \\
\hline Frankwich [2012] & 7.7 & 11.1 & 9 & 8.7 & 10.8 & 11 & $1.2 \%$ & $-1.00[-10.66,8.66]$ & \\
\hline Reijnders [2016] & 3.7 & 1.4 & 24 & 3.6 & 1.7 & 14 & $98.8 \%$ & $0.10[-0.95,1.15]$ & \\
\hline Total $(95 \% \mathrm{Cl})$ & & & 33 & & & 25 & $100.0 \%$ & $0.09[-0.96,1.13]$ & \\
\hline $\begin{array}{l}\text { Heterogeneity: } \mathrm{Tau}^{2}= \\
\text { Test for overall effect: }\end{array}$ & $\begin{array}{l}0.00 ; \mathrm{Ch} \\
\mathrm{Z}=0.16\end{array}$ & $\begin{array}{l}i^{2}=0 . \\
(P=C\end{array}$ & $\begin{array}{l}05, \mathrm{df}= \\
0.87)\end{array}$ & $=1(P=$ & 0.82); & $1^{2}=0 \%$ & & & $\begin{array}{ll}-10 & 0 \\
\text { Favours [Abx] } & \text { Favours [PL }\end{array}$ \\
\hline
\end{tabular}

\section{B. Body weight, $\mathrm{kg}$}

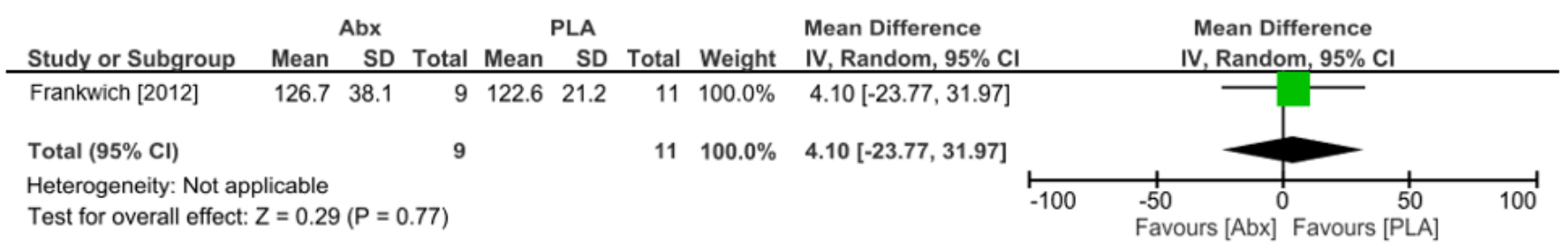

Figure 3 The results of meta-analysis of primary outcomes. Forest plot showing odds ratio and $95 \%$ confidence interval for each study along with study weight. Abx, antibiotics; CI, confidence interval; FPG, fasting plasma glucose; GLP, glucagon-like peptide; HOMA-IR, homeostasis model assessment of insulin resistance; MD, mean difference; SD, standard deviation.

(Figure 4B). The quality of evidence was very low due to limitations in study design and imprecision. While none of the studies reported waist circumferences, one study (15) documented the levels of three main SCFAs; acetate, butyrate, and propionate. There was moderate certainty evidence that antibiotics reduced fecal acetate and butyrate levels [(MD $-13.60 \mu \mathrm{mol} / \mathrm{g}$ (95\% CI: -22.43 to -4.77$)$, $\mathrm{MD}-7.60 \mu \mathrm{mol} / \mathrm{g}$ (95\% CI: -10.97 to -4.23$)$, respectively), though antibiotics resulted in little to no differences in propionate levels (MD - $1.10 \mu \mathrm{mol} / \mathrm{g}$ (95\% CI: -4.18 to 1.98 ) (Figure 4C). Adverse events were documented in two RCTs. One RCT (13) reported that one subject of the placebo group had a skin yeast infection, whereas in the antibiotics group one individual suffered from sun sensitivity, another had joint aches, night sweats, nausea, and dizziness, while two subjects had nausea. Another RCT (15) reported a few cases of mild gastrointestinal discomfort.

\section{Discussion}

The results of this up-to-date review cover two RCTs (placebo vs. DOX, placebo vs. VANCO vs. AMOX) and showed that antibiotics treatment did not significantly change HOMA-IR, FPG, body weight, and plasma GLP-1 levels as compared to placebo treatment, though antibiotics probably reduced fecal acetate and butyrate levels, which served as an indicator for an alteration of gut microbiota composition. This indicates that oral antibiotics treatment may not have much impact on the metabolic status in obese subjects immediately after antibiotics treatment, even though it changed the gut microbiota profile. We also found that other trials, which examined the effect of antibiotics on the metabolic status, did not always report outcomes important to our study, such as body weight or waist circumference. Although we expected antibiotics treatment to cause diarrhea, none of the RCTs reported the incidence of diarrhea. However, considering that several adverse events other than diarrhea were reported in the antibiotics group, we should be careful with the use of oral antibiotics.

Previous reports further support our conclusion that modulating the gut microbiota by oral antibiotics treatment may not have an impact on the metabolic status of an obese patient. More specifically, Mikkelsen et al. conducted a single-arm trial, by which they showed that four days of treatment with a broad-spectrum oral antibiotics cocktail containing VANCO $(500 \mathrm{mg} /$ day $)$, gentamycin (40 mg/day), and meropenem (500 mg/day) induced shifts in the gut microbiota profile, but had no clinically relevant short- or long-term effects on metabolic variables, such as FPG, insulin, and GLP-1 in 12 healthy, non-obese, glucose-tolerant males (32). 


\section{A. FPG, mmol/L}

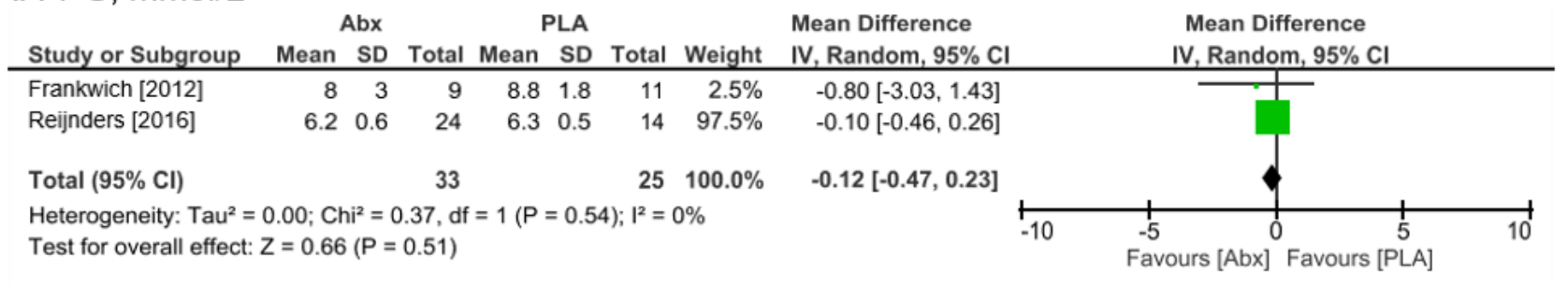

\section{B. Plasma GLP-1, pmol/L}

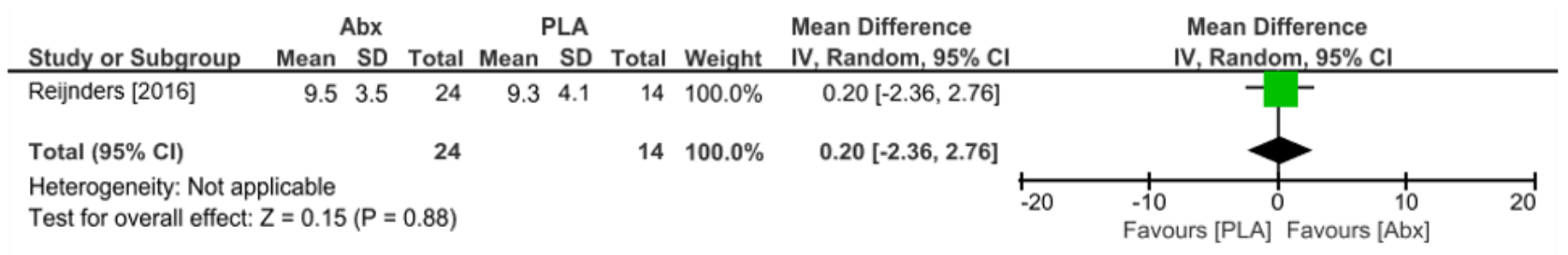

\section{Fecal SCFAs, $\mu \mathrm{mol} / \mathrm{g}$}

<acetate>

\begin{tabular}{|c|c|c|c|c|c|c|c|c|c|c|c|}
\hline \multirow[b]{2}{*}{ Study or Subgroup } & \multicolumn{3}{|c|}{$A b x$} & \multicolumn{3}{|c|}{ PLA } & \multirow[b]{2}{*}{ Weight } & \multirow{2}{*}{$\begin{array}{l}\text { Mean Difference } \\
\text { IV, Random, } 95 \% \mathrm{Cl}\end{array}$} & \multirow{2}{*}{\multicolumn{2}{|c|}{$\begin{array}{c}\text { Mean Difference } \\
\text { IV, Random, } 95 \% \text { Cl }\end{array}$}} & \\
\hline & Mean & SD & Total & Mean & SD & Total & & & & & \\
\hline Reijnders [2016] & 31.4 & 15.7 & 37 & 45 & 16.1 & 19 & $100.0 \%$ & $-13.60[-22.43,-4.77]$ & & & \\
\hline Total $(95 \% \mathrm{Cl})$ & & & 37 & & & 19 & $100.0 \%$ & $-13.60[-22.43,-4.77]$ & & & \\
\hline $\begin{array}{l}\text { Heterogeneity: Not ap } \\
\text { Test for overall effect: }\end{array}$ & $\begin{array}{l}\text { licable } \\
Z=3.02\end{array}$ & $(P=0$ & $0.003)$ & & & & & $\stackrel{\rightleftarrows}{-50}$ & $\begin{array}{l}-25 \\
\text { Favours [PLA] }\end{array}$ & Favours [Abx] & $\overrightarrow{50}$ \\
\hline
\end{tabular}

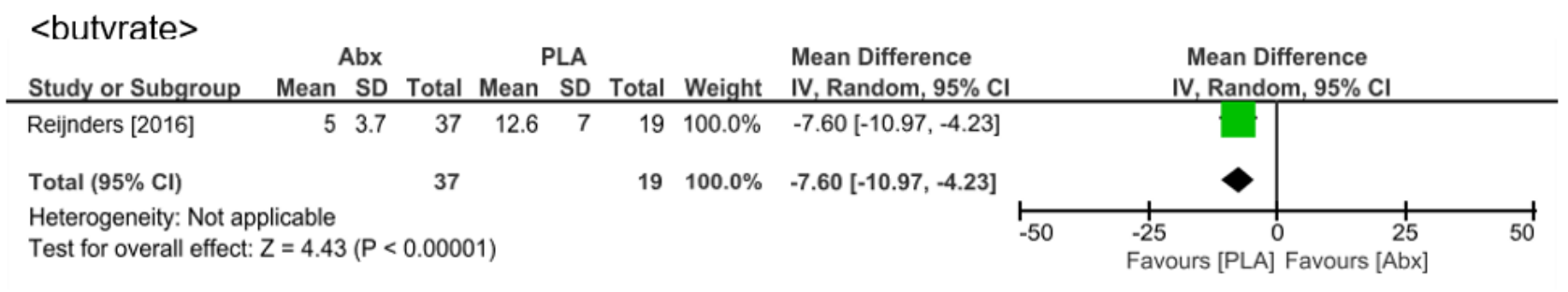

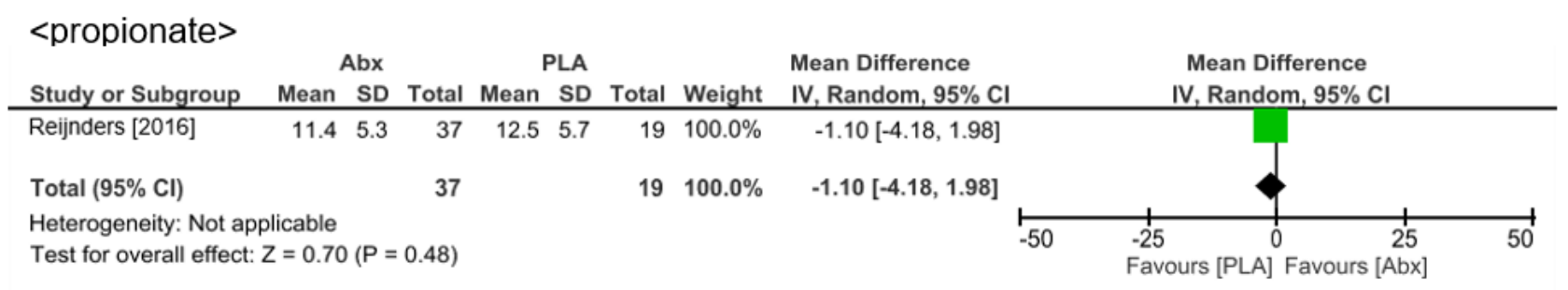

Figure 4 The results of meta-analysis of secondary outcomes. Forest plot showing odds ratio and $95 \%$ confidence interval for each study along with study weight. Abx, antibiotics; CI, confidence interval; FPG, fasting plasma glucose GLP, glucagon-like peptide; MD, mean difference; PLA, placebo; SCFA, short-chain fatty acid; SD, standard deviation. 
Interestingly, our results showed that oral antibiotics elicited little differences in plasma GLP-1 levels compared to placebo, with very low certainty evidence. Recent in vivo studies suggest a strong association between the gut microbiota in the small intestine and GLP-1 secretion $(33,34)$. Administration of probiotics could increase the GLP-1 secretion, resulting in reduced food intake and improved glucose tolerance in mice (35). However, our results suggest that oral antibiotics may not have much impact on the gut bacteria in the small intestine of humans.

Of note, antibiotics changed fecal acetate and butyrate levels. Antibiotic treatment lowered fecal SCFA levels possibly due to decreased numbers of gut bacteria. SCFAs are produced by bacterial fermentation of dietary carbohydrates (36), and have important effects on metabolic homeostasis by maintaining a balance in mucus production and secretion in the colon, promoting the generation of colonic regulatory $\mathrm{T}$ cells, and improving hepatic metabolism through activation of free fatty acid receptor 3 $(37,38)$. We observed that oral antibiotic treatment lowered fecal SCFA levels as compared to placebo administration with moderate certainty evidence. However, taking into consideration the beneficial effects of SCFAs, it can be said that decreasing SCFAs production by antibiotic treatment may have certain harmful effects. Therefore, again, it is necessary to be cautious when it comes to the clinical use of oral antibiotics for treatment of obesity.

On the other hand, there is evidence based on basic research, which supports the beneficial effects of antibiotics on the metabolic status. Previous in vivo studies have shown that 10 weeks of treatment with low doses of oral DOX, which is a broad-spectrum antibiotic belonging to the tetracycline class of antibiotics and inhibitors of matrix metalloproteinases (39), led to a decrease in systemic inflammation and improved glycemic control, lipid profiles, as well as islet morphology and function in $\mathrm{db} / \mathrm{db}$ mice (40). Taken the fact that gut microbial lipopolysaccharides and related metabolic endotoxemia are associated with the pathophysiology of obesity, as well as with the metabolic status of obese individuals $(6,41)$, it may be reasonable to hypothesize that oral antibiotic treatment targeting the gut microbiota would be beneficial for obese subjects. However, the results of the present study did not show any favorable effects of antibiotics, including DOX. The observed discrepancy between findings in humans and mice might be due to the differences in the natural, species-specific gut microbiome (42). It is important to pay attention to the complexities of translating the findings from an animal model to humans.

Although we included an RCT, which used rifaximin for intervention (26), no data was extracted from this RCT. Researchers in Egypt are now conducting an RCT using rifaximin as intervention treatment, entitled "Rifaximin Improves Insulin Resistance in Metabolic Syndrome and Reduces Insulin Requirement in Type 2 Diabetes." (25). Rifaximin has bactericidal activity against a broad spectrum of enteric pathogens and has been shown to reduce plasma lipopolysaccharide levels in chronic liver disease $(43,44)$. The results of this ongoing study will unravel the impact of rifaximin on the metabolic status in obese subjects in the future.

The present systematic review and meta-analysis have several limitations, which should be taken into consideration when interpreting the results. First, we included only two RCTs, and most results had low certainty of evidence. Further RCTs will be required to assess whether oral antibiotics have an impact on the metabolic status of obese subjects. Second, we could not analyze the long-term effects of oral antibiotics on the metabolic status of obese subjects. It may be more important to investigate the clinically relevant impact with a long-term follow-up approach.

\section{Conclusions}

In summary, the findings of the present study indicate that oral antibiotics treatment of obese individuals without bacterial infection did not alter their metabolic status, though it affected the gut microbiota of treated compared to placebo groups, suggesting that oral antibiotics treatment might not serve as a therapeutic approach for treatment of obesity and associated diseases. Further large and welldesigned RCTs will be warranted to confirm our findings and unravel the type of antibiotics, which would have an impact on the metabolic status of obese subjects.

\section{Acknowledgments}

We thank Dr. Ryuhei So and all the members of the Systematic Review Workshop Peer Support Group for their cooperation in conducting the study.

Funding: This work was supported by the Japan Society for the Promotion of Science KAKENHI Grant [grant number 19K23944]. The funders played no role in the design and conduct of the study, the collection, management, analysis, and interpretation of the data, the preparation, review, or approval of the manuscript, or the decision to submit the manuscript for publication. 


\section{Footnote}

Reporting Checklist: The authors have completed the PRISMA reporting checklist. Available at http://dx.doi. org/10.21037/atm-20-1007a

Conflicts of Interest: All authors have completed the ICMJE uniform disclosure form (available at http://dx.doi. org/10.21037/atm-20-1007a). Yuki Kataoka serves as an unpaid editorial board member of Annals of Translational Medicine from Jul 2018 to Jun 2020. The other authors have no conflicts of interest to declare.

Ethical Statement: The authors are accountable for all aspects of the work in ensuring that questions related to the accuracy or integrity of any part of the work are appropriately investigated and resolved.

Open Access Statement: This is an Open Access article distributed in accordance with the Creative Commons Attribution-NonCommercial-NoDerivs 4.0 International License (CC BY-NC-ND 4.0), which permits the noncommercial replication and distribution of the article with the strict proviso that no changes or edits are made and the original work is properly cited (including links to both the formal publication through the relevant DOI and the license). See: https://creativecommons.org/licenses/by-nc-nd/4.0/.

\section{References}

1. Blüher M. Obesity: global epidemiology and pathogenesis. Nat Rev Endocrinol 2019;15:288-98.

2. Hotamisligil GS. Inflammation and metabolic disorders. Nature 2006;444:860-7.

3. Heymsfield SB, Wadden TA. Mechanisms, Pathophysiology, and Management of Obesity. N Engl J Med 2017;376:254-66.

4. Turnbaugh PJ, Ley RE, Mahowald MA, et al. An obesityassociated gut microbiome with increased capacity for energy harvest. Nature. 2006;444:1027-31.

5. Turnbaugh PJ, Hamady M, Yatsunenko T, et al. A core gut microbiome in obese and lean twins. Nature 2009;457:480-4.

6. Yoshida N, Emoto T, Yamashita T, et al. Bacteroides vulgatus and Bacteroides dorei Reduce Gut Microbial Lipopolysaccharide Production and Inhibit Atherosclerosis. Circulation 2018;138:2486-98.

7. Kimura I, Ozawa K, Inoue D, et al. The gut microbiota suppresses insulin-mediated fat accumulation via the short-chain fatty acid receptor GPR43. Nat Commun 2013;4:1829.

8. Liu R, Hong J, Xu X, et al. Gut microbiome and serum metabolome alterations in obesity and after weight-loss intervention. Nat Med 2017;23:859-68.

9. Castaner O, Goday A, Park YM, et al. The Gut Microbiome Profile in Obesity: A Systematic Review. Int J Endocrinol 2018;2018:4095789.

10. Hillman ET, Lu H, Yao T, et al. Microbial Ecology along the Gastrointestinal Tract. Microbes Environ 2017;32:300-13.

11. Bauer PV, Duca FA, Waise TMZ, et al. Metformin Alters Upper Small Intestinal Microbiota that Impact a GlucoseSGLT1-Sensing Glucoregulatory Pathway. Cell Metab 2018;27:101-17.e5.

12. Bäckhed F, Manchester JK, Semenkovich CF, et al. Mechanisms underlying the resistance to diet-induced obesity in germ-free mice. Proc Natl Acad Sci U S A 2007;104:979-84.

13. Frankwich K, Tibble C, Torres-Gonzalez M, et al. Proof of Concept: Matrix metalloproteinase inhibitor decreases inflammation and improves muscle insulin sensitivity in people with type 2 diabetes. J Inflamm (Lond) 2012;9:35.

14. Vrieze A, Out C, Fuentes $S$, et al. Impact of oral vancomycin on gut microbiota, bile acid metabolism, and insulin sensitivity. J Hepatol 2014;60:824-31.

15. Reijnders D, Goossens GH, Hermes GD, et al. Effects of Gut Microbiota Manipulation by Antibiotics on Host Metabolism in Obese Humans: a Randomized DoubleBlind Placebo-Controlled Trial. Cell Metab 2016;24:63-74.

16. Moher D, Liberati A, Tetzlaff J, et al. Preferred Reporting Items for Systematic Reviews and Meta-Analyses: The PRISMA Statement. Ann Intern Med 2009;151:264-9.

17. Moher D, Liberati A, Tetzlaff J, et al. Preferred reporting items for systematic reviews and meta-analyses: The PRISMA statement. Int J Surg 2010;8:336-41.

18. Higgins JPT TJ, Chandler J, Cumpston M, et al., editors. Cochrane Handbook for Systematic Reviews of Interventions version 6.0 (updated July 2019). Cochrane. Available online: www.training.cochrane.org/handbook. 2019.

19. Ouzzani M, Hammady H, Fedorowicz Z, et al. Rayyan-a web and mobile app for systematic reviews. Syst Rev 2016;5:210.

20. Sterne JAC, Savović J, Page MJ, et al. RoB 2: a revised tool for assessing risk of bias in randomised trials. BMJ 2019;366:14898.

21. Andrews JC, Schünemann HJ, Oxman AD, et al. GRADE 
guidelines: 15. Going from evidence to recommendationdeterminants of a recommendation's direction and strength. J Clin Epidemiol 2013;66:726-35.

22. Copenhagen: The Nordic Cochrane Centre TCC. Review Manager (RevMan) [Computer program]. Version 5.3. 2014.

23. Higgins JPT, Thompson SG, Deeks JJ, et al. Measuring inconsistency in meta-analyses. BMJ 2003;327:557-60.

24. Reijnders D, Goossens GH, Hermes GDA, et al. Erratum: Effects of Gut Microbiota Manipulation by Antibiotics on Host Metabolism in Obese Humans: A Randomized Double-Blind Placebo-Controlled Trial (Cell Metabolism (2016) 24(1) (63-74) (S1550413116303023) (10.1016/ j.cmet.2016.06.016)). Cell Metab 2016;24:341.

25. Nct. Rifaximin Improves Gut Dysbiosis in Insulin Resistance and Type 2 Diabetes. Available online: https:// clinicaltrialsgov/show/NCT037581442018.

26. Vizuete J, Randall C, Taboada C. Rifaximin for the treatment of weight loss. Am J Gastroenterol 2012;107:S590.

27. Reijnders D, Goossens GH, Neis EP, et al. Effects of gut microbiota manipulation by antibiotics on host metabolism in obese humans. Obes Facts 2015;8:23.

28. Balliu E, McNurlan M, Golub L, et al. Doxycycline for the treatment of insulin resistance in overweight and obese individuals. Preliminary data. Endocrine Reviews 2017;38. Available online: https://endo.confex.com/endo/2017endo/ meetingapp.cgi/Paper/30069

29. Baumgartner S, Reijnders D, Konings M, et al. The effects of amoxicillin and vancomycin on parameters reflecting cholesterol metabolism. Chem Phys Lipids 2017;207:239-45.

30. Reijnders D, Goossens GH, Hermes GDA, et al. ShortTerm Microbiota Manipulation and Forearm Substrate Metabolism in Obese Men: A Randomized, Double-Blind, Placebo-Controlled Trial. Obes Facts 2018;11:318-26.

31. Egger M, Smith GD, Schneider M, et al. Bias in metaanalysis detected by a simple, graphical test. BMJ 1997;315:629-34.

32. Mikkelsen KH, Frost M, Bahl MI, et al. Effect of Antibiotics on Gut Microbiota, Gut Hormones and Glucose Metabolism. PLoS One 2015;10:e142352.

Cite this article as: Yoshida N, Saito Y, Tsujimoto Y, Taito S, Banno M, Kataoka Y, Yamashita T, Hirata K. The impact of antibiotics on the metabolic status of obese adults without bacterial infection: a systematic review and meta-analysis. Ann Transl Med 2020;8(17):1059. doi: 10.21037/atm-20-1007a
33. Everard A, Cani PD. Gut microbiota and GLP-1. Rev Endocr Metab Disord 2014;15:189-96.

34. Grasset E, Puel A, Charpentier J, et al. A Specific Gut Microbiota Dysbiosis of Type 2 Diabetic Mice Induces GLP-1 Resistance through an Enteric NODependent and Gut-Brain Axis Mechanism. Cell Metab 2017;25:1075-90.e5.

35. Yadav H, Lee JH, Lloyd J, et al. Beneficial metabolic effects of a probiotic via butyrate-induced GLP-1 hormone secretion. J Biol Chem 2013;288:25088-97.

36. Makki K, Deehan EC, Walter J, et al. The Impact of Dietary Fiber on Gut Microbiota in Host Health and Disease. Cell Host Microbe 2018;23:705-15.

37. Furusawa Y, Obata Y, Fukuda S, et al. Commensal microbe-derived butyrate induces the differentiation of colonic regulatory T cells. Nature 2013;504:446-50.

38. Shimizu H, Masujima Y, Ushiroda C, et al. Dietary shortchain fatty acid intake improves the hepatic metabolic condition via FFAR3. Sci Rep 2019;9:16574.

39. Mazor R, Friedmann-Morvinski D, Alsaigh T, et al. Cleavage of the leptin receptor by matrix metalloproteinase-2 promotes leptin resistance and obesity in mice. Sci Transl Med 2018;10:eaah6324.

40. Wang N, Tian X, Chen Y, et al. Low dose doxycycline decreases systemic inflammation and improves glycemic control, lipid profiles, and islet morphology and function in db/db mice. Sci Rep 2017;7:14707.

41. Shi H, Kokoeva MV, Inouye K, et al. TLR4 links innate immunity and fatty acid-induced insulin resistance. J Clin Invest 2006;116:3015-25.

42. Nguyen TLA, Vieira-Silva S, Liston A, et al. How informative is the mouse for human gut microbiota research? Dis Model Mech 2015;8:1-16.

43. Bajaj JS, Heuman DM, Sanyal AJ, et al. Modulation of the Metabiome by Rifaximin in Patients with Cirrhosis and Minimal Hepatic Encephalopathy. PLoS One 2013;8:e60042.

44. Hugenholtz F, de Vos WM. Mouse models for human intestinal microbiota research: a critical evaluation. Cell Mol Life Sci 2018;75:149-60. 


\begin{tabular}{|c|c|}
\hline Set\# & Searched for \\
\hline$\# 1$ & overweight[mh] \\
\hline \#2 & "metabolic syndrome"[mh] \\
\hline \#3 & overnutrition[mh] \\
\hline \#4 & "Weight gain"[mh] \\
\hline \#5 & \#1 OR \#2 OR \#3 Or \#4 \\
\hline \#6 & Obes* $[$ tiab] \\
\hline \#7 & overweight[tiab] \\
\hline \#8 & "metabolic syndrome"[tiab] \\
\hline$\# 9$ & overnutrition[tiab] \\
\hline \#10 & "Weight gain"[tiab] \\
\hline \#11 & \#6 OR \#7 OR \#8 OR \#9 OR \#10 \\
\hline$\# 12$ & \#5 OR \#11 \\
\hline \#13 & "Anti-Bacterial Agents"[mh] \\
\hline \#14 & "Anti-Bacterial Agents"[Pharmacological Action] \\
\hline \#15 & $\# 13$ OR \#14 \\
\hline \#16 & antibiotic ${ }^{*}[$ tiab] \\
\hline \#17 & antibacteri*[tiab] \\
\hline \#18 & anti*bacter*[tiab] \\
\hline \#19 & bacteriocid*[tiab] \\
\hline \#20 & bactericid $^{\star}[$ tiab] \\
\hline \#21 & anti*microbial[tiab] \\
\hline \#22 & ciprofloxacin[tiab] \\
\hline \#23 & metronidazole[tiab] \\
\hline \#24 & levamisole[tiab] \\
\hline \#25 & ornidazole[tiab] \\
\hline \#26 & fusidin[tiab] \\
\hline \#27 & rifaximin[tiab] \\
\hline \#28 & vancomycin[tiab] \\
\hline \#29 & "fusidic acid"[tiab] \\
\hline \#30 & nitazoxanide[tiab] \\
\hline \#31 & teicoplanin[tiab] \\
\hline \#32 & rifampicin[tiab] \\
\hline \#33 & bacitracin[tiab] \\
\hline \#34 & fidaxomicin[tiab] \\
\hline \#35 & amoxicillin[tiab] \\
\hline \#36 & azithromycin[tiab] \\
\hline \#37 & cephalosporin*[tiab] \\
\hline \#38 & cephalexin[tiab] \\
\hline \#39 & clarithromycin[tiab] \\
\hline \#40 & clindamycin[tiab] \\
\hline \#41 & doxycycline[tiab] \\
\hline \#42 & erythromycin[tiab] \\
\hline \#43 & flouroquinolone*[tiab] \\
\hline \#44 & levofloxacin[tiab] \\
\hline \#45 & macrolide*[tiab] \\
\hline \#46 & nitrofurantoin[tiab] \\
\hline \#47 & penicillin[tiab] \\
\hline \#48 & tetracycline[tiab] \\
\hline \#49 & trimethoprim[tiab] \\
\hline \#50 & $\begin{array}{l}\# 16 \text { OR \#17 OR \#18 OR \#19 OR \#20 OR \#21 OR \#22 OR \#23 OR \#24 OR \#25 OR \#26 OR \#27 OR \#28 OR \#29 OR } \\
\text { \#30 OR \#31 OR \#32 OR \#33 OR \#34 OR \#35 OR \#36 OR \#37 OR \#38 OR \#39 OR \#40 OR \#41 OR \#42 OR \#43 OR } \\
\# 44 \text { OR \#45 OR \#46 OR \#47 OR \#48 OR \#49 }\end{array}$ \\
\hline \#51 & $\# 15$ OR \#50 \\
\hline$\# 52$ & \#12 AND \#51 \\
\hline \#53 & randomized controlled trial [pt] \\
\hline \#54 & controlled clinical trial [pt] \\
\hline \#55 & randomized [tiab] \\
\hline \#56 & placebo [tiab] \\
\hline \#57 & clinical trials as topic [mesh: noexp] \\
\hline \#58 & randomly [tiab] \\
\hline \#59 & trial [ti] \\
\hline \#60 & \#53 OR \#54 OR \#55 OR \#56 OR \#57 OR \#58 OR \#59 \\
\hline \#61 & animals [mh] NOT humans [mh] \\
\hline \#62 & \#60 NOT \#61 \\
\hline \#63 & \#52 AND \#62 \\
\hline
\end{tabular}


Table S2 Search strategy of EMBASE ${ }^{\circledR}$

\begin{tabular}{|c|c|}
\hline Set\# & Searched for \\
\hline S2 & EMB.EXACT.EXPLODE(“overnutrition”) \\
\hline S3 & (EMB.EXACT.EXPLODE(“body weight gain”)) \\
\hline S4 & $\left(a b\left(\right.\right.$ Obes $\left.^{\star}\right)$ OR ti(Obes $\left.\left.{ }^{\star}\right)\right)$ \\
\hline S5 & (ab(overweight) OR ti(overweight)) \\
\hline S6 & (ab(“metabolic syndrome”) OR ti(“metabolic syndrome”)) \\
\hline S7 & (ab(overnutrition) OR ti(overnutrition)) \\
\hline S8 & (ab(“Weight gain") OR ti(“Weight gain")) \\
\hline s9 & S8 OR S7 OR S6 OR S5 OR S4 OR S3 OR S2 \\
\hline S10 & (EMB.EXACT.EXPLODE(“antibiotic agent”)) \\
\hline S11 & $\left(\right.$ ab(antibiotic $\left.{ }^{\star}\right)$ OR ti(antibiotic $\left.)\right)$ \\
\hline S12 & $($ ab(antibacteri*) OR ti(antibacteri*)) \\
\hline S15 & $($ ab(anti bacter $)$ OR ti(anti bacter $))$ \\
\hline S16 & $\left(\right.$ ab $($ bacteriocid $)$ OR ti(bacteriocid $\left.\left.{ }^{*}\right)\right)$ \\
\hline S17 & $\left(\right.$ ab $\left(\right.$ bactericid $\left.^{\star}\right)$ OR ti( bactericid $\left.\left.^{\star}\right)\right)$ \\
\hline S18 & (ab(anti*microbial) OR ti(anti*microbial)) \\
\hline S19 & (ab(ciprofloxacin) OR ti(ciprofloxacin)) \\
\hline S20 & (ab(metronidazole) OR ti(metronidazole)) \\
\hline S21 & (ab(levamisole) OR ti(levamisole)) \\
\hline S22 & (ab(ornidazole) OR ti(ornidazole)) \\
\hline S23 & (ab(fusidin) OR ti(fusidin)) \\
\hline S24 & (ab(rifaximin) OR ti(rifaximin)) \\
\hline S25 & (ab(vancomycin) OR ti(vancomycin)) \\
\hline S26 & (ab("fusidic acid") OR ti("fusidic acid")) \\
\hline S27 & (ab(nitazoxanide) OR ti(nitazoxanide)) \\
\hline S28 & (ab(teicoplanin) OR ti(teicoplanin)) \\
\hline S29 & (ab(rifampicin) OR ti(rifampicin)) \\
\hline S30 & (ab(bacitracin) OR ti(bacitracin)) \\
\hline S31 & (ab(fidaxomicin) OR ti(fidaxomicin)) \\
\hline S32 & (ab(amoxicillin) OR ti(amoxicillin)) \\
\hline S33 & (ab(azithromycin) OR ti(azithromycin)) \\
\hline S34 & $($ (ab(cephalosporin*) OR ti(cephalosporin*)) \\
\hline S35 & (ab(cephalexin) OR ti(cephalexin)) \\
\hline S36 & (ab(clarithromycin) OR ti(clarithromycin)) \\
\hline S37 & (ab(clindamycin) OR ti(clindamycin)) \\
\hline S38 & (ab(doxycycline) OR ti(doxycycline)) \\
\hline S39 & (ab(erythromycin) OR ti(erythromycin)) \\
\hline S40 & (ab(flouroquinolone*) OR ti(flouroquinolone $\left.e^{\star}\right)$ ) \\
\hline S41 & (ab(levofloxacin) OR ti(levofloxacin)) \\
\hline S42 & $\left(\mathrm{ab}\left(\right.\right.$ macrolide $\left.^{\star}\right)$ OR ti(macrolide $\left.\left.{ }^{\star}\right)\right)$ \\
\hline$S 43$ & (ab(nitrofurantoin) OR ti(nitrofurantoin)) \\
\hline S44 & (ab(penicillin) OR ti(penicillin)) \\
\hline S45 & (ab(tetracycline) OR ti(tetracycline)) \\
\hline S46 & (ab(trimethoprim) OR ti(trimethoprim)) \\
\hline S47 & $\begin{array}{l}\text { S46 OR S45 OR S44 OR S43 OR S42 OR S41 OR S40 OR S39 OR S38 OR S } 37 \text { OR S } 36 \text { OR S35 OR S34 OR S } 33 \text { OR S } 32 \\
\text { OR S31 OR S30 OR S29 OR S28 OR S27 OR S26 OR S25 OR S24 OR S23 OR S22 OR S21 OR S20 OR S19 OR S18 OR } \\
\text { S17 OR S16 OR S15 OR S12 OR S11 OR S10 }\end{array}$ \\
\hline S48 & S47 AND S9 \\
\hline S49 & $\left(\left(\right.\right.$ ab $\left(\right.$ random$\left.^{\star}\right)$ OR ti(random*)) OR (ab(placebo*) OR ti(placebo*)) OR (ab(double NEAR/1 blind*) OR ti(double NEAR/1 blind $\left.\left.\left.{ }^{\star}\right)\right)\right)$ \\
\hline S50 & S49 AND S48 \\
\hline
\end{tabular}

${ }^{*}$, duplicates are removed from the search, but included in the result count. ${ }^{\circ}$, duplicates are removed from the search and from the result count. 
Table S3 Search strategy of Cochrane Central Register of Controlled Trials (CENTRAL)

\begin{tabular}{|c|c|}
\hline Set\# & Searched for \\
\hline$\# 1$ & MeSH descriptor:[overweight]explode all trees \\
\hline \#2 & MeSH descriptor:[Metabolic Syndrome]explode all trees \\
\hline \#3 & MeSH descriptor:[Overnutrition]explode all trees \\
\hline \#4 & MeSH descriptor:[Weight Gain]explode all trees \\
\hline \#5 & \#1 OR \#2 OR \#3 OR \#4 \\
\hline \#6 & $\left(\mathrm{Obes}^{*}\right): \mathrm{ti}, \mathrm{ab}, \mathrm{kw}$ \\
\hline \#7 & (overweight):ti,ab,kw \\
\hline \#8 & (“metabolic syndrome”):ti,ab,kw \\
\hline$\# 9$ & (overnutrition):ti,ab,kw \\
\hline \#10 & (“Weight gain"):ti,ab,kw \\
\hline \#11 & \#6 OR \#7 OR \#8 OR \#9 OR \#10 \\
\hline \#12 & \#5 OR \#11 \\
\hline$\# 13$ & MeSH descriptor:[Anti-Bacterial Agents]explode all trees \\
\hline \#14 & (antibiotic*):ti,ab,kw \\
\hline \#15 & $($ antibacteri*):ti,ab,kw \\
\hline \#16 & $($ anti*bacter*):ti,ab,kw \\
\hline \#17 & (bacteriocid*):ti,ab,kw \\
\hline \#18 & $\left(\right.$ bactericid $\left.^{\star}\right): \mathrm{ti}, \mathrm{ab}, \mathrm{kw}$ \\
\hline \#19 & (antimicrobial):ti,ab,kw \\
\hline \#20 & (ciprofloxacin):ti,ab,kw \\
\hline \#21 & (metronidazole):ti,ab,kw \\
\hline \#22 & (levamisole):ti,ab,kw \\
\hline \#23 & (ornidazole):ti,ab,kw \\
\hline \#24 & (fusidin):ti,ab,kw \\
\hline \#25 & (rifaximin):ti,ab,kw \\
\hline \#26 & (vancomycin):ti,ab,kw \\
\hline \#27 & ("fusidic acid"):ti,ab,kw \\
\hline \#28 & (nitazoxanide):ti,ab,kw \\
\hline \#29 & (teicoplanin):ti,ab,kw \\
\hline \#30 & (rifampicin):ti,ab,kw \\
\hline \#31 & (bacitracin):ti,ab,kw \\
\hline \#32 & (fidaxomicin):ti,ab,kw \\
\hline \#33 & (amoxicillin):ti,ab,kw \\
\hline \#34 & (azithromycin):ti,ab,kw \\
\hline \#35 & (cephalosporin*):ti,ab,kw \\
\hline \#36 & (cephalexin):ti,ab,kw \\
\hline \#37 & (clarithromycin):ti,ab,kw \\
\hline \#38 & (clindamycin):ti,ab,kw \\
\hline \#39 & (doxycycline):ti,ab,kw \\
\hline \#40 & (erythromycin):ti,ab,kw \\
\hline \#41 & (flouroquinolone*):ti,ab,kw \\
\hline \#42 & (levofloxacin):ti,ab,kw \\
\hline \#43 & $($ macrolide*):ti,ab,kw \\
\hline \#44 & (nitrofurantoin):ti,ab,kw \\
\hline \#45 & (penicillin):ti,ab,kw \\
\hline \#46 & (tetracycline):ti,ab,kw \\
\hline \#47 & (trimethoprim):ti,ab,kw \\
\hline \#48 & $\begin{array}{l}\# 14 \text { OR \#15 OR \#16 OR \#17 OR \#18 OR \#19 OR \#20 OR \#21 OR \#22 OR \#23 OR \#24 OR \#25 OR \#26 OR \#27 OR } \\
\text { \#28 OR \#29 OR \#30 OR \#31 OR \#32 OR \#33 OR \#34 OR \#35 OR \#36 OR \#37 OR \#38 OR \#39 OR \#40 OR \#41 OR } \\
\text { \#42 OR \#43 OR \#44 OR \#45 OR \#46 OR \#47 }\end{array}$ \\
\hline \#49 & $\# 13$ OR \#48 \\
\hline$\# 50$ & \#12 AND \#49 \\
\hline
\end{tabular}

